\title{
Fluoroscopically guided anterior atlantoaxial transarticular screws: a feasibility and trajectory study using CT-based simulation software
}

\author{
Mary R.A. Padua, MD ${ }^{\mathrm{a}}$, Jin S. Yeom, MD, PhD ${ }^{\mathrm{a} *}$, So Y. Lee ${ }^{\mathrm{a}}$, So M. Lee ${ }^{\mathrm{a}}$, \\ Ho-Joong Kim, MD, $\mathrm{PhD}^{\mathrm{a}}$, Bong-Soon Chang, $\mathrm{MD}, \mathrm{PhD}^{\mathrm{b}}$, Choon-Ki Lee, $\mathrm{MD}, \mathrm{PhD}^{\mathrm{b}}$, \\ K. Daniel Riew, MD, $\mathrm{PhD}^{\mathrm{c}}$ \\ ${ }^{a}$ Spine Center and Department of Orthopaedic Surgery, Seoul National University College of Medicine and Seoul National University Bundang Hospital, \\ 166 Gumiro, Bundang-ku, Sungnam 463-707, Republic of Korea \\ ${ }^{\mathrm{b}}$ Department of Orthopaedic Surgery, Seoul National University College of Medicine and Seoul National University Hospital, 101 Daehangno, Jongno-gu, \\ Seoul 110-744, Republic of Korea \\ ${ }^{\mathrm{c}}$ Department of Orthopaedic Surgery, Washington University in St Louis, 660 S. Euclid Ave., Campus Box 8233, St Louis, MO 63110, USA
}

Received 27 January 2013; accepted 4 May 2013

Abstract

BACKGROUND CONTEXT: Anterior transarticular screw (ATAS) fixation has been suggested as a viable alternative to posterior stabilization. However, we are not aware of previous reports attempting to establish the usefulness of specific fluoroscopic landmark-guided trajectories in the use of ATAS, and we could find no reference to it in a computerized search using MEDLINE.

PURPOSE: To determine the anatomic feasibility of ATAS placement using defined fluoroscopic landmarks to guide screw trajectory.

STUDY DESIGN: Evaluation using three-dimensional screw insertion simulation software and 1.0-mm-interval computed tomographic scans.

PATIENT SAMPLE: Computed tomographic scans of 100 patients including 50 men and 50 women.

OUTCOME MEASURES: Incidence of violation of the vertebral artery groove of $\mathrm{C} 1$ and $\mathrm{C} 2$, the spinal canal, and the atlanto-occipital joint and screw lengths and lengths of $\mathrm{C} 1$ and $\mathrm{C} 2$ purchase. METHODS: Four screw trajectories were determined: promontory screw (PS), single central facet (CF) screw, and medial (MF) and lateral (LF) double facet screws. Placement of a 4.0-mm screw was simulated using defined fluoroscopic landmarks for each trajectory. The previously mentioned outcome measures were evaluated and compared for the four trajectories. This study was not supported by any financial sources, and there is no topic-specific potential conflict of interest with this study.

RESULTS: No violation of the $\mathrm{C} 1$ or $\mathrm{C} 2$ vertebral artery groove or of the spinal canal was observed for any of the screw types. Screw lengths and the length of $\mathrm{C} 2$ purchase were by far the longest for PS (40.4 \pm 2.8 and $25.7 \pm 2.1 \mathrm{~mm}$, respectively; $\mathrm{p}<.001$ in all post hoc comparisons). The length of $\mathrm{C} 1$ purchase was longer for CF $(16.4 \pm 2.3 \mathrm{~mm})$ and LF $(15.8 \pm 1.6 \mathrm{~mm})$ than PS $(14.7 \pm 2.0 \mathrm{~mm})$ and $\mathrm{MF}(14.6 \pm 2.4 \mathrm{~mm})(\mathrm{p} \leq .001$, respectively). There was no atlanto-occipital joint violation if the length of $\mathrm{C} 1$ purchase was set at $12 \mathrm{~mm}$ for $\mathrm{CF}$ and $\mathrm{LF}$ and at $10 \mathrm{~mm}$ for PS and MF.

FDA device/drug status: Not approved for this indication (anterior atlantoaxial transarticular screws).

Author disclosures: MRAP: Nothing to disclose. JSY: Speaking/Teaching Arrangements: Medtronic (B). SYL: Nothing to disclose. SML: Nothing to disclose. $\boldsymbol{H}$-JK: Nothing to disclose. B-SC: Stock Ownership: Bio Alpha, Inc. (B). $\boldsymbol{C}$ - $\boldsymbol{K L}$ : Nothing to disclose. $\boldsymbol{K D \boldsymbol { R }}$ : Grants/grants pending: Medtronic (IDE Participation, Paid directly to institution/employer); Royalties: Osprey (D), Medtronic (G), Biomet (F); Stock/stock options: Osprey (C), Expanding Orthopedics (C), Spineology (C), Spinal Kinetics (C), Amedica (C), Nexgen Spine (B), Vertiflex (C), Benvenue (C), Paradigm Spine $(\mathrm{C})$.
The disclosure key can be found on the Table of Contents and at www. TheSpineJournalOnline.com.

Institutional review board status: This study was approved by the institutional review board of Seoul National University Bundang Hospital.

* Corresponding author. Spine Center and Department of Orthopaedic Surgery, Seoul National University College of Medicine and Seoul National University Bundang Hospital, 166 Gumiro, Bundang-ku, Sungnam 463-707, Republic of Korea. Tel.: (82) 31-787-7195; fax: (82) 31787-4056.

E-mail address: highcervical@gmail.com (J.S. Yeom) 
CONCLUSIONS: Our results suggest that it may be possible to place ATASs without violating the vertebral artery groove, spinal canal, or the atlanto-occipital joint by using the described entry points, trajectories, and fluoroscopic landmarks. (c) 2013 Elsevier Inc. All rights reserved.

Keywords: $\quad$ Atlantoaxial fixation; Screw fixation; Anterior atlantoaxial transarticular screws; Vertebral artery injury; atlantooccipital joint violation

\section{Introduction}

Anterior transarticular screw (ATAS) fixation across the atlantoaxial joint has been suggested as a viable alternative to posterior stabilization in the upper cervical spine [1-10]. Fixation through the anterior route may be advantageous in some patients requiring subsequent stabilization after anterior decompression because it obviates the need for additional posterior surgery [1-3]. Examples include cases of odontoid resection or after anterior release and reduction of a fixed atlantoaxial dislocation. In addition, it may be a logical alternative when posterior screw placement would be unsafe, unfeasible, or challenging because of osteolysis in infectious or tumorous conditions [1] or variations in the local anatomy such as aberrant or anomalous vertebral artery [11-13], severe high-riding vertebral artery [13-16], and narrow pars interarticularis [17]. It may also be used as a complementary option if previous posterior fixation and fusion have failed to provide adequate stability $[1,18]$. Furthermore, it may be a reasonable option in selected cases in polytrauma, respiratory-compromised [4], or hemodynamically vulnerable elderly patients $[5,6]$, wherein a prone position may increase operative morbidity and/or mortality.

Since the introduction of this procedure $[9,10]$, clinical studies have reported that this procedure has favorable early clinical outcomes $[1,7]$ with high fusion rates $[1-3,8]$, only minor complications [1-3,5], and less anatomic risk for the vertebral artery compared with posterior transarticular screws [16]. Several studies have also shown that the biomechanical properties of ATAS are comparable to posterior fixation techniques such as posterior transarticular screws [19] and posterior C1 lateral mass screw combined with C2 pedicle screw/rod systems [20,21]. Variable entry points and trajectories of the screws including single [4-10,17] or double facet screws [17], and screws inserted through the C2 promontory [1-3] have been described in the literature. However, most of the previously suggested screw trajectories used a fixed range of trajectory angles [2-5], which have some limitations. Even if a specific angle is selected within this range, the exact screw location may vary widely with the anatomic differences among individuals $[1,11,14,17]$. In addition, even if the trajectory angle is determined individually using preoperative computed tomographic (CT) scan images [1], it may not be appropriate in many cases, as the trajectory angles may have to be modified intraoperatively after reduction of the atlantoaxial joint.

Although screw entry points can be recognized relatively easily because they are visible or palpable through the anterior retropharyngeal approach, the exact location of the screw inside the bony structures and assessment of screw cutout may be difficult. Even with C-arm fluoroscopy, it would be difficult to identify the location of the screw in relation to bony and neurovascular structures using only two-dimensional fluoroscopic images because the threedimensional anatomy is quite complex in this area. However, considering that C-arm fluoroscopy is the only tool available for verifying the screw location during surgery in most circumstances, it would be reasonable to identify reliable fluoroscopic landmarks and to determine trajectories guided by them for safe screw insertion in each individual patient. Equally important would be the assessment of appropriate screw lengths to avoid inadvertent atlantooccipital joint encroachment. To our knowledge, however, no published literature has investigated the ideal trajectories guided by specific fluoroscopic landmarks and to assess their feasibility in the use of ATAS, and we could find no reference to it in a computerized search using MEDLINE. Therefore, the purpose of this study was to determine the possible trajectories of ATAS guided by specific fluoroscopic landmarks using three-dimensional screw placement simulation software. Next, we assessed the feasibility of these trajectories by investigating the frequency of violation of the $\mathrm{C} 1$ and $\mathrm{C} 2$ vertebral artery grooves [22], spinal canal, and atlanto-occipital joint.

\section{Materials and methods}

\section{Selection criteria}

This study was approved by our institutional review board. One-millimeter-interval CT scans (Mx8000 IDT; Philips Medical Systems, Best, The Netherlands) of the cervical spine taken from June 2009 to September 2012 at the corresponding author's institution were initially included for analyses. Exclusion criteria were CT scans of patients under 20 years of age; those with unsatisfactory imaging of the craniovertebral junction area including occipital condyles, $\mathrm{C} 1$, and C2; CT scans with severe metal artifact caused by dental 
implants; postoperative CT scans; severe arthrosis or destruction of the craniovertebral junction area; atlantoaxial instability; and congenital anomalies, fractures, infection, and tumors at the craniovertebral junction area. Equal numbers of consecutive patients were selected for each gender from the patients fulfilling the selection criteria.

\section{Computer simulation}

Three-dimensional screw trajectory software (Vworks; Cybermed, Inc., Reston, VA, USA) was used for simulation of screw insertions. A three-dimensional model, along with coronal and sagittal images, was reconstructed using 1.0mm-interval axial CT scan images of the craniovertebral junction. During simulation, the insertion points and trajectories of the guide pin and screws can be assessed using these multiplanar and three-dimensional images simultaneously (Fig. 1). In addition, this software can reconstruct fluoroscopic images from the axial CT scan images, which can be seen together with the multiplanar and threedimensional images during simulation. This allowed confirmation of the intended trajectories and end points of the screws in the fluoroscopic images by simultaneously observing its exact location in three-dimensional space.

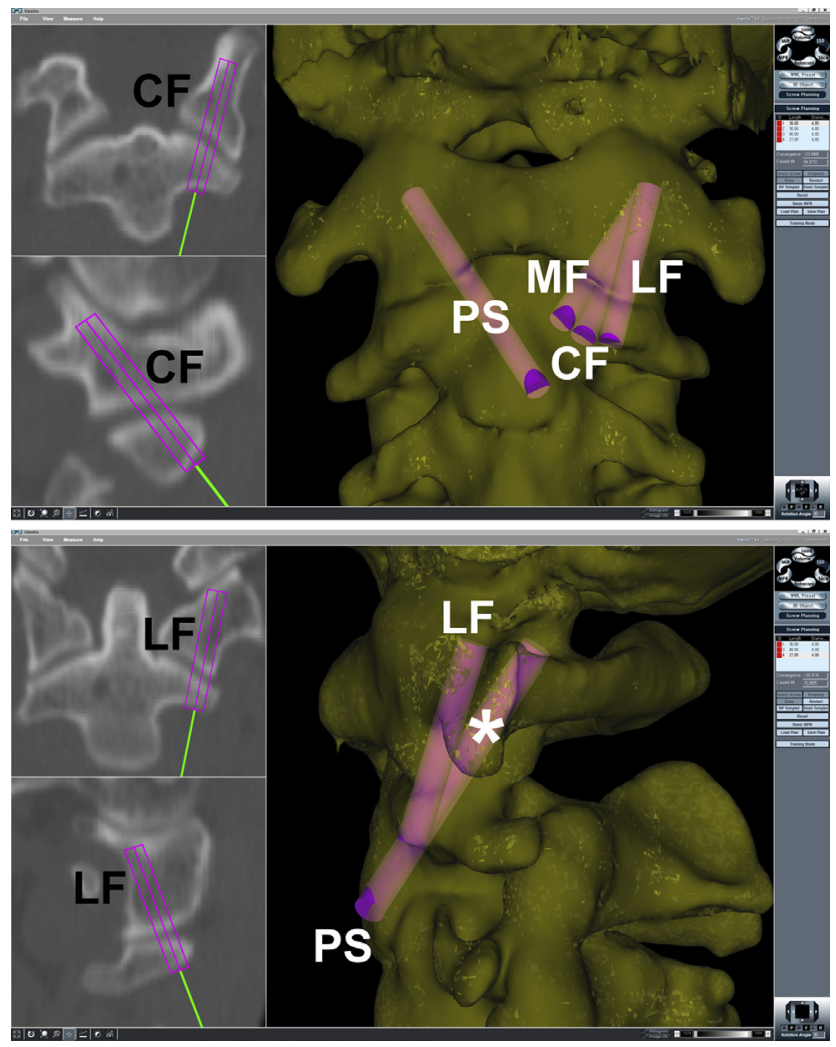

Fig. 1. (Top) Trajectories of four screw types are shown on a threedimensional image, and the trajectory of a CF screw is shown on the two-dimensional images. (Bottom) Trajectories of four screw types are shown on a three-dimensional image, and the trajectory of an LF screw is shown on the two-dimensional images. CF and MF screws are overlapped with each other (asterisk). CF, central facet screw; MF, medial double facet screw; LF, lateral double facet screw.
Lengths of the screws and C1 and C2 purchase can be measured using this software.

\section{Screw entry points and trajectories}

Taking into account that there are relatively large areas for ATAS placement and that one-sided incision is to be used for bilateral screw fixation, four screw trajectories were determined. For the fixation of the atlantoaxial joint contralateral to the skin incision and retropharyngeal approach, the entry point was set at the ipsilateral (thus contralateral to the joint) promontory (Fig. 1, Top). This was named as promontory screw (PS). For ipsilateral screw fixation, the entry point was set at just below the anterior prominent ridge of the axis, located caudal to the anterior joint line of the $\mathrm{C} 1-\mathrm{C} 2$ facet joint (Fig. 1, Top). For this, we determined trajectories for a single screw and double screws. The former was named as single central facet screw (CF) and the latter as medial (MF) and lateral (LF) double facet screws. The entry points and trajectories for the screws were determined after pilot simulation in 40 patients.

For PS, the entry point was set at a point $5 \mathrm{~mm}$ cranial to the anterior edge of the $\mathrm{C} 2$ end plate and 2 to $3 \mathrm{~mm}$ lateral from the midline to the contralateral side (Fig. 1, Top), to provide an allowable distance between the screw head and the C2-C3 intervertebral disc to prevent adjacent level ossification development [23,24]. For facet screws (CF, MF, and LF), the area below the anterior prominent ridge of the axis was divided into medial and lateral parts by a vertical line bisecting the anterior margin of the $\mathrm{C} 1-\mathrm{C} 2$ facet joint. The entry point was at the junction of the two parts for $\mathrm{CF}$, in the medial part for $\mathrm{MF}$, and in the lateral part for $\mathrm{LF}$ (Fig. 1, Top).

All trajectories were determined using the landmarks visible on anteroposterior and lateral fluoroscopic images, taking into account that fluoroscopy is the only guide during surgery in most circumstances. On the anteroposterior view, the trajectories of all screws were aimed at a point at the level of the superolateral corner of the superior articular process of $\mathrm{C} 1$, which provides 2 to $3 \mathrm{~mm}$ clearance from the lateral margin of the lateral mass (Fig. 2, Left). On the lateral view, the trajectories of PS, CF, and MF were aimed at a point on the line between the superoposterior corner of the superior articular process of $\mathrm{C} 1$ and the superior end of the anterior arch of $\mathrm{C} 1$, with 2 to $3 \mathrm{~mm}$ clearance from the posterior margin of the superior articular process (Fig. 2, Right). A true lateral view defined here as complete overlap of the posterior cortex of the superior articular processes on both sides cannot be overemphasized and should be visualized to avoid injury to the vertebral artery posteriorly. For LF, a different aiming point was used on the lateral view to avoid collision with MF. It was aimed at the midpoint between the superoposterior corner of the superior articular process of $\mathrm{C} 1$ and the superior end of the anterior arch of C1 (Fig. 2, Right). It should be emphasized that all these aiming points delineate only the 

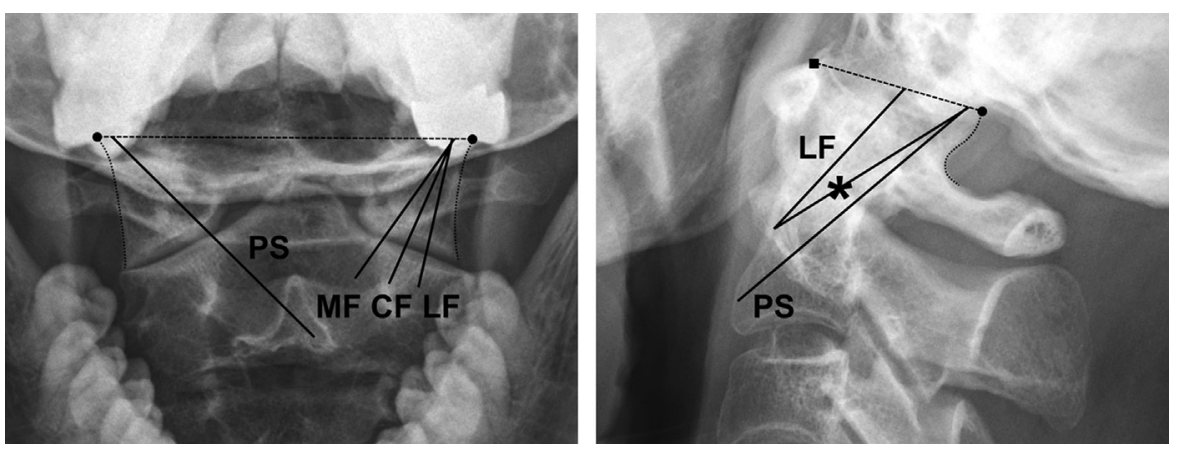

Fig. 2. The trajectories of the four types of screws are shown on anteroposterior (Left) and lateral (Right) radiographs. (Left) All screws are aimed at a point at the level of the superolateral corner of the superior articular process of $\mathrm{C} 1$ (a round dot on each side), which provides 2 to $3 \mathrm{~mm}$ clearance from the lateral margin of the lateral mass (a dotted curve on each side). (Right) PS, CF (asterisk), and MF (asterisk) are aimed at a point on the line between the superoposterior corner of the superior articular process of $\mathrm{C} 1$ (a round dot) and the superior end of the anterior arch of $\mathrm{C} 1$ (a quadrangular dot), with 2 to 3 $\mathrm{mm}$ clearance from the posterior margin of the superior articular process (a dotted curve), and LF is aimed at the midpoint of the line. PS, promontory screw; $\mathrm{CF}$, central facet screw; MF, medial double facet screw; LF, lateral double facet screw.

direction of the screws but not the depth. If a screw is inserted to the depth of the aiming point, it may be too deep and the atlanto-occipital joint may be violated. This will be discussed subsequently.

\section{Screw length and lengths of C1/C2 purchase}

All screw diameters were set at $4.0 \mathrm{~mm}$, following the diameter used in previous clinical and biomechanical studies [2-6,19-21]. The maximum allowable screw lengths in the absence of any cortical breach on reconstructed twodimensional trajectory views or three-dimensional images were measured. In addition, the length of $\mathrm{C} 1$ purchase was measured from the cortical margin at the inferior articular surface of $\mathrm{C} 1$ to the end point of the screw. The length of the $\mathrm{C} 2$ purchase was defined as the maximum allowable screw length minus the length of $\mathrm{C} 1$ purchase. They were measured for each of the four types of screw.

\section{Data analyses}

All simulations were assessed for encroachment of the vertebral artery groove of $\mathrm{C} 1$ and $\mathrm{C} 2$ [22] and the spinal canal. The screw lengths along with lengths of $\mathrm{C} 1$ and $\mathrm{C} 2$ purchase were compared for all screw types. The frequency of atlanto-occipital joint violation was evaluated using the length of $\mathrm{C} 1$ screw purchase as reference.

\section{Statistical analyses}

Measured lengths were compared among the four screw types using repeated-measures one-way analysis of variance test followed by post hoc Tukey tests for individual comparisons. For comparison of lengths between male and female, $t$ test was used. The frequencies of atlantooccipital violations were compared using Cochran Q test followed by post hoc multiple McNemar tests with Bonferroni correction for individual comparisons. The statistical software used was GraphPad Prism version 5.00 (GraphPad
Software, San Diego, CA, USA) and MedCalc for Windows, version 12.3.0.0 (MedCalc Software, Mariakerke, Belgium). The level of significance was set at a two-tailed $\mathrm{p}<.05$.

\section{Results}

\section{Patient demographics}

Computed tomographic scans of 100 patients including 50 men and 50 women were used for this study. The mean age was $50 \pm 8$ years (range 29-70). We simulated insertion of $100 \mathrm{PS}, \mathrm{CF}, \mathrm{MF}$, and LF screws respectively, performing a total of 400 screw insertion simulations.

\section{Violation of the vertebral artery groove of $C 1$ and $C 2$ and the spinal canal}

Violation of the vertebral artery groove of either $\mathrm{C} 1$ or $\mathrm{C} 2$ was not observed during simulations by any screw type following the specified entry points and trajectories. Neither was there any violation of the spinal canal.

\section{Screw length and lengths of C1/C2 purchase}

The screw lengths and lengths of $\mathrm{C} 1 / \mathrm{C} 2$ purchase are summarized in Table 1 and Fig. 3. As shown, these lengths were significantly longer for males compared with females $(\mathrm{p}<.05)$ in most cases. Overall, the screw length was by far the longest $(\mathrm{p}<.001$ in all post hoc comparisons) for PS $(40.4 \pm 2.8 \mathrm{~mm})$, followed by CF $(26.5 \pm 2.6 \mathrm{~mm})$, which was significantly longer $(\mathrm{p}<.001$, respectively) than MF $(25.1 \pm 2.8 \mathrm{~mm})$ and LF $(24.6 \pm 2.0 \mathrm{~mm})$, between which the difference was not statistically significant $(p=.094)$. The length of $\mathrm{C} 2$ purchase was by far the longest $(\mathrm{p}<.001$ in all post hoc comparisons) for PS $(25.7 \pm 2.1 \mathrm{~mm})$, followed by MF $(10.5 \pm 1.4 \mathrm{~mm})$, which was significantly longer $(p=.029)$ than $C F(10.1 \pm 1.3 \mathrm{~mm})$, which again was significantly longer $(p<.001)$ than $\operatorname{LF}(8.7 \pm 1.3 \mathrm{~mm})$. For the length 
Table 1

Measured screw length and lengths of $\mathrm{C} 1 / \mathrm{C} 2$ purchase

\begin{tabular}{|c|c|c|c|c|c|}
\hline Measured length & PS & MF & $\mathrm{CF}$ & $\mathrm{LF}$ & $\mathrm{p}^{*}$ \\
\hline \multicolumn{6}{|l|}{ Screw length (mm) } \\
\hline All $(n=100)$ & $40.4 \pm 2.8$ & $25.1 \pm 2.8$ & $26.5 \pm 2.6$ & $24.6 \pm 2.0$ & $\mathrm{PS}>\mathrm{CF}>\mathrm{MF}=\mathrm{LF}$ \\
\hline Male $(n=50)$ & $41.6 \pm 2.7$ & $25.9 \pm 3.0$ & $27.7 \pm 2.6$ & $25.6 \pm 1.9$ & $\mathrm{PS}>\mathrm{CF}>\mathrm{MF}=\mathrm{LF}$ \\
\hline Female $(n=50)$ & $39.3 \pm 2.5$ & $24.4 \pm 2.4$ & $25.3 \pm 1.9$ & $23.6 \pm 1.5$ & $\mathrm{PS}>\mathrm{CF}=\mathrm{MF}=\mathrm{LF}$ \\
\hline $\mathrm{p}^{\dagger}$ & $<.001$ & .010 & $<.001$ & $<.001$ & \\
\hline \multicolumn{6}{|l|}{ C1 purchase $(\mathrm{mm})$} \\
\hline All $(n=100)$ & $14.7 \pm 2.0$ & $14.6 \pm 2.4$ & $16.4 \pm 2.3$ & $15.8 \pm 1.6$ & $\mathrm{CF}=\mathrm{LF}>\mathrm{MF}=\mathrm{PS}$ \\
\hline Male $(n=50)$ & $14.7 \pm 2.1$ & $15.1 \pm 2.6$ & $17.2 \pm 2.4$ & $16.2 \pm 1.7$ & $\mathrm{CF}>\mathrm{LF}>\mathrm{MF}=\mathrm{PS}$ \\
\hline Female $(n=50)$ & $14.7 \pm 1.8$ & $14.1 \pm 2.1$ & $15.6 \pm 1.9$ & $15.4 \pm 1.4$ & $\mathrm{CF}=\mathrm{LF}=\mathrm{PS}=\mathrm{MF}$ \\
\hline $\mathrm{p}^{\dagger}$ & .881 & .038 & $<.001$ & .011 & \\
\hline \multicolumn{6}{|l|}{$\mathrm{C} 2$ purchase $(\mathrm{mm})$} \\
\hline All $(n=100)$ & $25.7 \pm 2.1$ & $10.5 \pm 1.4$ & $10.1 \pm 1.3$ & $8.7 \pm 1.3$ & $\mathrm{PS}>\mathrm{MF}>\mathrm{CF}>\mathrm{LF}$ \\
\hline Male $(n=50)$ & $26.9 \pm 1.5$ & $10.7 \pm 1.6$ & $10.5 \pm 1.3$ & $9.3 \pm 1.3$ & $\mathrm{PS}>\mathrm{MF}=\mathrm{CF}>\mathrm{LF}$ \\
\hline Female $(n=50)$ & $24.6 \pm 2.0$ & $10.3 \pm 1.2$ & $9.7 \pm 1.1$ & $8.1 \pm 1.0$ & $\mathrm{PS}>\mathrm{MF}>\mathrm{CF}>\mathrm{LF}$ \\
\hline $\mathrm{p}^{\dagger}$ & $<.001$ & .114 & .001 & $<.001$ & \\
\hline
\end{tabular}

PS, promontory screw; CF, central facet screw; MF, medial double facet screw; LF, lateral double facet screw.

Values are mean \pm standard deviation.

* Post hoc Tukey test after repeated-measures one-way analysis of variance test; " =" indicates p $>.05$ and " $>$ " indicates p $<.05$ in post hoc comparison.

$\dagger \mathrm{p}$ Values calculated by the $t$ test to compare males and females.

of $\mathrm{C} 1$ purchase, $\mathrm{CF}(16.4 \pm 2.3 \mathrm{~mm})$ was longer than LF $(15.8 \pm 1.6 \mathrm{~mm})$ but without statistically significant difference $(\mathrm{p}=.063)$. Both were significantly longer than PS $(14.7 \pm 2.0 \mathrm{~mm})$ and MF $(14.6 \pm 2.4 \mathrm{~mm})(\mathrm{p} \leq .001$, respectively), between which the difference was not statistically significant $(\mathrm{p}=1.000)$.

\section{Frequency of atlanto-occipital joint violation in terms of the length of $\mathrm{Cl}$ purchase}

The evaluated frequency of atlanto-occipital joint violation is summarized in Table 2 and Fig. 4. The number of joint violations increased proportionately with the length of $\mathrm{C} 1$ purchase. At $10 \mathrm{~mm}$ of $\mathrm{C} 1$ purchase, the joint was not violated by any type of screw. CF and LF had no violation with up to $12 \mathrm{~mm}$ of $\mathrm{C} 1$ purchase. At 11 and 12 $\mathrm{mm}$, the frequency of joint violation was less than $4 \%$ for MF and PS. A marked increase in the number of joint violation (up to 39\%) was noted at 13 and $14 \mathrm{~mm}$ purchase lengths. At these lengths, joint violation was significantly more common for MF and PS than for $\mathrm{LF}$ and $\mathrm{CF}$ ( $\mathrm{p}<.05$ in all post hoc comparisons).

\section{Discussion}

Anterior transarticular screws have been suggested as an effective alternative to posterior fixation in the upper cervical spine in some situations [1-10]. Despite its known advantages over posterior fixation, the technique for safe insertion of the screws with reference to trajectories and screw dimensions still deserves further investigation. To our knowledge, there have been no reports on the use of specific landmarks in fluoroscopically guided trajectories. Lack of these supportive data motivated the authors to perform this investigation. In determining screw trajectories, we have to consider three points: practical applicability during real surgery, important anatomic structures to be avoided, and feasibility of $\mathrm{C}$-arm guidance.

\section{Screw entry points}

Variable entry points have been defined in the literature [1-10,17,19]. In the present study, we assessed the feasibility of four types of screws. Promontory screw was assumed to be used for the $\mathrm{C} 1-\mathrm{C} 2$ facet on the side contralateral to the skin incision, whereas $\mathrm{CF}, \mathrm{MF}$, and LF were for the ipsilateral facet. For PS, the entry point was previously described to be on the anterior edge of the $\mathrm{C} 2$ end plate and a few millimeters lateral to the midline, on the side ipsilateral to the $\mathrm{C} 1-\mathrm{C} 2$ joint to be fixated [1-3]. We moved the entry point $5 \mathrm{~mm}$ cranially to decrease the risk of adjacent level ossification $[23,24]$ at $\mathrm{C} 2-\mathrm{C} 3$. In addition, we moved the entry point to the side contralateral to the $\mathrm{C} 1-\mathrm{C} 2$ joint

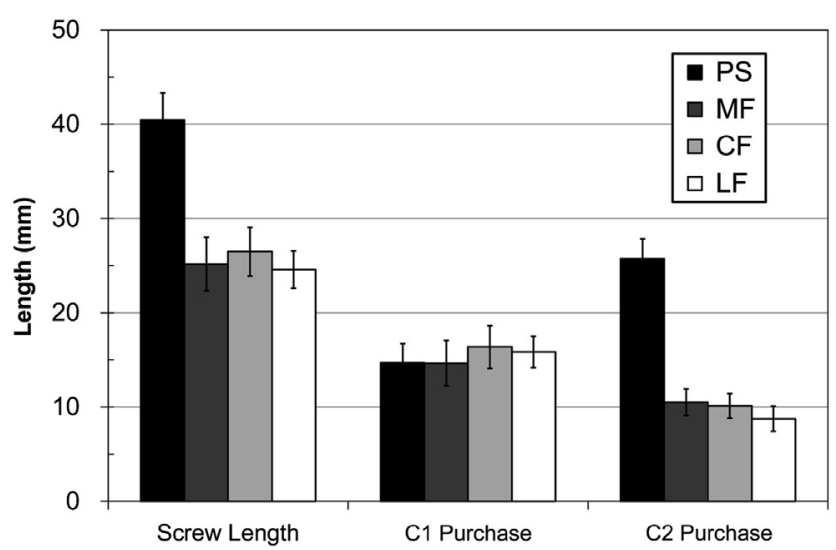

Fig. 3. Mean (with standard deviation) lengths of screws and $\mathrm{C} 1 / \mathrm{C} 2$ purchase for the four types of screws are shown as a bar chart. PS, promontory screw; CF, central facet screw; MF, medial double facet screw; LF, lateral double facet screw. 
Table 2

Frequency of atlanto-occipital joint violation in terms of length of $\mathrm{C} 1$ purchase $(n=100)$

\begin{tabular}{lcclll}
\hline $\begin{array}{l}\mathrm{C} 1 \\
\text { purchase }(\mathrm{mm})\end{array}$ & PS (\%) & MF (\%) & $\mathrm{CF}(\%)$ & $\mathrm{LF}(\%)$ & $\mathrm{p}^{*}$ \\
\hline 10 & 0 & 0 & 0 & 0 & 1.000 \\
11 & 3 & 1 & 0 & 0 & .066 \\
12 & 4 & 4 & 0 & 0 & $\mathrm{MF}=\mathrm{PS}=\mathrm{CF}=\mathrm{LF}$ \\
13 & 12 & 17 & 2 & 1 & $\mathrm{MF}=\mathrm{PS}>\mathrm{CF}=\mathrm{LF}$ \\
14 & 28 & 39 & 6 & 8 & $\mathrm{MF}=\mathrm{PS}>\mathrm{LF}=\mathrm{CF}$ \\
\hline
\end{tabular}

PS, promontory screw; CF, central facet screw; MF, medial double facet screw; LF, lateral double facet screw.

* Cochran $Q$ test after post hoc comparison using multiple McNemar tests with Bonferroni correction; "=" indicates $\mathrm{p}>.05$ and " $>$ " indicates $\mathrm{p}<.05$ in post hoc comparison.

to be fixated, to maintain a transcorporal pathway for the screw and to minimize the possibility of the screw cutting out of the anterior cortex of the $\mathrm{C} 2$ promontory. The entry points of $\mathrm{CF}$ and MF were similar to those used in previous studies $[4-9,17]$. The use of double facet screws as an alternative to single facet screws has been suggested by Lu et al. [17] to provide improved joint stabilization but without description of entry points and trajectories. Although double screws were feasible with our simulations, we would discourage the routine use of double facet screws particularly because of possible technical errors during LF insertion. This will be described subsequently.

\section{Screw trajectories}

Important anatomic structures to be avoided during ATAS placement are the spinal cord medially, the vertebral artery posterolaterally at $\mathrm{C} 1$ and $\mathrm{C} 2$, and the atlanto-occipital joint cranially. To prevent atlanto-occipital joint violation, it should be emphasized that the $\mathrm{C} 1$ lateral masses on both sides have a "bow-tie shape" on the coronal plane [25] so that their height is longer in the lateral part and shorter in the medial part, as seen in Fig. 2, Left. Therefore, to maximize the C1

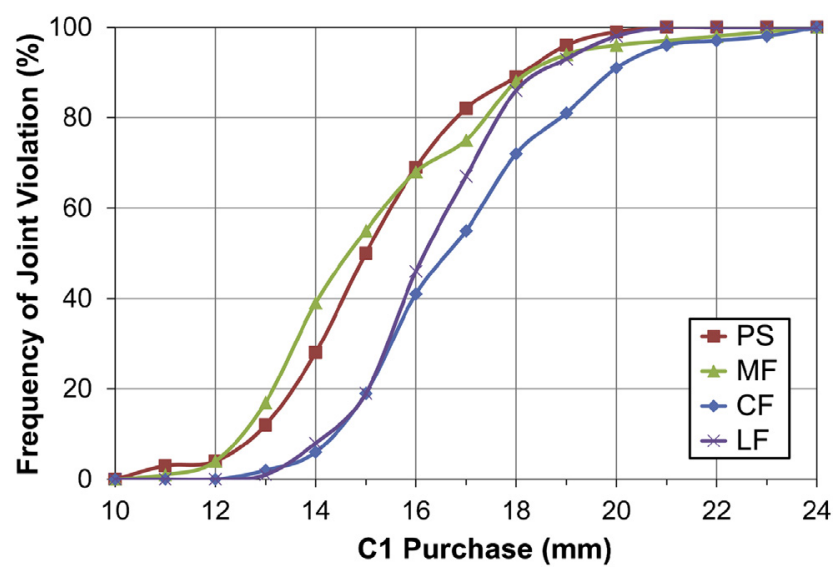

Fig. 4. Frequency of atlanto-occipital joint violation in terms of length of $\mathrm{C} 1$ purchase for the four types of screws is shown. PS, promontory screw; $\mathrm{CF}$, central facet screw; MF, medial double facet screw; LF, lateral double facet screw. purchase and to avoid atlanto-occipital joint violation, we provided lateral angulation of the screws. As an added advantage, the resulting screw trajectories were near perpendicular to the $\mathrm{C} 1-\mathrm{C} 2$ joint line providing better biomechanical stability. However, if angulated too laterally, the screw will violate the lateral cortex at the level of $\mathrm{C} 1$ transverse foramen or above/below it, leading to vertebral artery injury. Keeping in mind that the radius of the screw was $2 \mathrm{~mm}$, we aimed at a point that provided 2 to $3 \mathrm{~mm}$ clearance from the lateral margin of the lateral mass (Fig. 2, Left). On the lateral view, for $\mathrm{PS}, \mathrm{CF}$, and MF, we aimed posteriorly to maximize $\mathrm{C} 1$ purchase again. In addition, posterior angulation will permit a more cranial skin incision, making the approach, screw placement, and intra-articular bone grafting easier. However, too much posterior angulation will lead to violation of the posterior cortex of the superior articular process of $\mathrm{C} 1$ and result in vertebral artery injury. Therefore, we provided a safety margin of 2 to $3 \mathrm{~mm}$, considering that the radius of the screw is $2 \mathrm{~mm}$. Of note, on the lateral view, it may seem that the screw tip is located in the spinal canal (Fig 2, Right). But on the AP view, it is obvious that the screw is lateral to the canal and crossing the $\mathrm{C} 1-\mathrm{C} 2$ joint. For LF, a more vertical, thus less posterior angulation was given, for two reasons. First, we wanted to avoid collision with MF. Second, we wanted to avoid the vertebral artery groove of $\mathrm{C} 2$, which is located posterior to the screw trajectory [22]. Because the entry point of the LF is more lateral than other screws, it is closer to the groove than the other screws (Fig. 5). Therefore, if the same posterior angulation is used, the risk of violating the groove might be increased. By decreasing the posterior angulation, we were able to avoid violating the groove in all our cases.

\section{Injury to the spinal cord and vertebral artery}

There does not appear to be much risk of spinal cord injury with any of the four screw types, as long as the

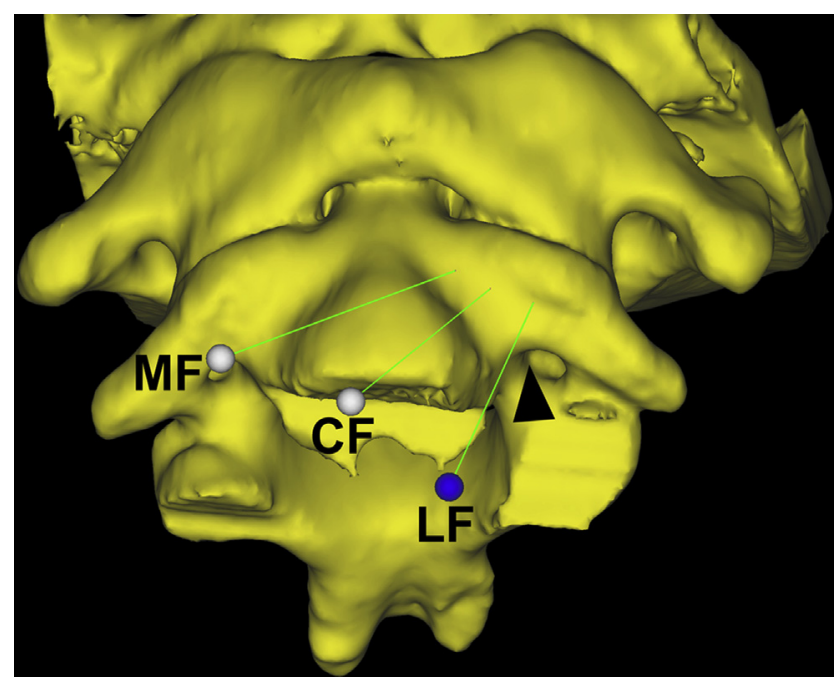

Fig. 5. An anteroinferior view of the $\mathrm{C} 2$ shows the proximity of the LF screw and the vertebral artery groove of C2 (arrowhead). CF, central facet screw; MF, medial double facet screw; LF, lateral double facet screw. 
trajectory is angulated laterally as suggested. However, if the trajectory is directed more medially during real surgery, particularly with medial screws such as PS and MF, the screw tip may injure the spinal cord.

Although there was no cortical violation by any of the four screw types in our simulation, technical errors during real surgery may lead to misplacement of the screws or injury to the vertebral artery. At $\mathrm{C} 1$, if a screw is inserted more posteriorly and/or more laterally than the suggested trajectories, it may penetrate the posterior or lateral cortex of the superior articular process and injure the vertebral artery at the posterior arch of $\mathrm{C} 1$. Violation of the vertebral artery groove of $\mathrm{C} 2$ [22] may result in an arterial injury. Particularly, care should be taken during LF screw placement in real surgery because it passes closest to the groove (Fig. 5). Erroneous posterior slip during LF screw hole creation should be avoided because the groove is located immediately posterior to the LF screw trajectory (Fig. 5). This is probable because direct observation of the entry point during pilot hole creation may not be easy. Placement of a too lateral entry point should also be avoided because of its closer proximity to the transverse foramen of C2 laterally. In addition, too posterior angulation should be avoided for LF to prevent violation of the vertebral artery groove of $\mathrm{C} 2$ (Fig. 5) as described previously. Considering these technical issues, we would not recommend the routine use of LF screws.

\section{Screw length, lengths of C1/C2 purchase, and prevention of atlanto-occipital joint violation}

In the present study, the screw length and length of $\mathrm{C} 2$ purchase were by far the greatest for PS because of its distal entry point at the $\mathrm{C} 2$ vertebral body (Fig. 1, Top). The length of C2 purchase of the three facet screws decreased from a medial to lateral entry point $(\mathrm{MF}>\mathrm{CF}>\mathrm{LF}$, Table 1) after the decreasing bone volume between the entry point and atlantoaxial joint from the medial to the lateral part. $\mathrm{C} 1$ purchase was significantly longer with the two lateral screws (CF and LF) compared with the two medial screws (PS and MF). This is because of the longer height of the $\mathrm{C} 1$ lateral mass laterally compared with medially as described previously. LF has a shorter $\mathrm{C} 1$ purchase than CF (Table 1) because LF has less posterior angulation in the lateral view. CF and LF had no violation of the atlantooccipital joint with up to $12 \mathrm{~mm}$ of $\mathrm{C} 1$ purchase, whereas PS and MF had no violation with up to only $10 \mathrm{~mm}$ of C1 purchase (Table 2).

Previous reports have emphasized the use of shorter screws to avoid injury to the atlanto-occipital joint $[1,17]$. Screw lengths can be determined during real surgery in the following two ways. First, when a guide pin is inserted toward the aiming point of the selected screw trajectory, insertion is temporarily halted at the level of the transverse process of $\mathrm{C} 1$. This level is low enough to ensure no violation of the atlanto-occipital joint by the guide pins. Guide pin length is measured at this level. Then, the pin is advanced guided by both tactile feedback and fluoroscopy until it closely approaches but does not penetrate the cortical bone at the aiming point. The pin length is measured again. Then, a screw length is determined between the two measured lengths taking into account that the superolateral edge of superior articular process of $\mathrm{C} 1$ is narrow compared with the screw width ( $4.0 \mathrm{~mm}$ or so). In addition, if the lag screw technique is to be applied to compress the facet joint space, even shorter screws should be used. Second, the length of C2 purchase is measured using a guide pin, and a fixed safe length based on our measurements may be added. Taking into account the results summarized in Table 2 and Fig. 4, $10 \mathrm{~mm}$ may be added for PS and MF and $12 \mathrm{~mm}$ for CF and LF. Although it may underestimate the actual length of the screws, it ensures safer insertion. One can also use a combination of the two methods. Of note, a true anteroposterior view of the atlanto-occipital joint line, if achievable, would be the best confirmation of having avoided its violation. In contrast, the lateral view is not helpful because the joint line is low medially and high laterally (Fig. 2, Left) such that joint violation is undetectable on this view.

\section{Preference for screws}

For the fixation on the side contralateral to the skin incision, we believe the PS would be the best choice because it is easiest to place and provides the longest $\mathrm{C} 2$ purchase. For the ipsilateral side, we prefer $\mathrm{CF}$ because it provides the longest $\mathrm{C} 1$ purchase without risking vertebral artery injury. If double screw fixation is required on the ipsilateral side for stronger fixation, use of MF and LF is recommended with careful insertion of the LF to prevent injury to the vertebral artery.

\section{Limitations of the present study}

As with any study, there are a number of limitations with ours. First of all, computer simulations may have certain disadvantages compared with cadaveric studies. Because they enable placing the screws in an ideal position by doing repeated simulations $[26,27]$, it is possible that we have underestimated the actual incidence of atlanto-occipital joint violation or vertebral artery injury [28,29]. However, this is an inevitable compromise to obtain a larger sample size and, at the same time, compare different screw types using the same specimen. Second, we did not take into account soft tissues. For example, placement of ipsilateral and laterally angulated facet screws may require extensive retraction of the midline structures [30]. The use of a tubular retractor or instruments for odontoid screw fixation may facilitate this procedure [2,3]. Third, although this is the largest series that we are aware of, there are infinite variations when it comes to human anatomy [25] so that there may be exceptional cases such as extremely abnormal course of the vertebral artery or acquired alterations in the osseous anatomy of the atlas 
and axis, which may prohibit the use of ATAS. Fourth, we believe that it may be difficult for those with minimal experience using such screws to recall most of the presented information after casual reading of this article, given its technical information. However, this is exactly the type of information that an inexperienced surgeon attempting one of these screws is likely to appreciate. There are few surgeons with extensive experience using these screws clinically, and most surgeons will only resort to using these screws only in rare cases. Infrequently used screws pose the greatest risk for injury to vital structures. Therefore, we believe that the main value of this article is to serve as a reference for those attempting such screws without vast previous experience. Finally, height, age, race, and the original diagnosis of our subjects were not considered.

Despite these limitations, we believe that this study has its unique strengths. As far as we know, this is the largest series to analyze the feasibility of ATAS. Reliable fluoroscopic landmarks were determined and evaluated with three-dimensional and fluoroscopic simulation using finecut CT scan images. The authors were able to recommend threshold lengths of $\mathrm{C} 1$ purchase for all types of screws, to ensure preservation of the atlanto-occipital joint during this procedure.

\section{Conclusions}

To our knowledge, this is the first feasibility study on the trajectories of ATAS guided by specific fluoroscopic landmarks and the largest series analyzing ATAS trajectories. Violation of the vertebral artery groove and the spinal canal was not observed in any of the screw types using 4.0$\mathrm{mm}$-diameter screws. Screw lengths and the length of $\mathrm{C} 2$ purchase were longest for PS. The length of $\mathrm{C} 1$ purchase was longer for CF and LF than PS and MF. There was no atlanto-occipital joint violation if the length of $\mathrm{C} 1$ purchase was set at $12 \mathrm{~mm}$ for CF and LF and at $10 \mathrm{~mm}$ for PS and MF.

\section{Acknowledgments}

We thank and acknowledge Ms Yoon Ju Kwon and Ms Junga Park, the spine research coordinators at our institution, for their contributions to the project.

\section{References}

[1] Koller H, Kammermeier V, Ulbricht D, et al. Anterior retropharyngeal fixation C1-C2 for stabilization of atlantoaxial instabilities: study of feasibility, technical description and preliminary results. Eur Spine J 2006;15:1326-38.

[2] Wu YS, Chi YL, Wang XY, et al. Microendoscopic anterior approach for irreducible atlantoaxial dislocation: surgical techniques and preliminary results. J Spinal Disord Tech 2010;23:113-20.

[3] Wang J, Zhou Y, Zhang Z, et al. Minimally invasive anterior transarticular screw fixation and microendoscopic bone graft for atlantoaxial instability. Eur Spine J 2012;21:1568-74.
[4] Reindl R, Sen M, Aebi M. Anterior instrumentation for traumatic C1C2 instability. Spine 2003;28:E329-33.

[5] Agrillo U, Mastronardi L. Acute combination fracture of atlas and axis: "triple" anterior screw fixation in a 92-year-old man: technical note. Surg Neurol 2006;65:58-62.

[6] Apostolides PJ, Theodore N, Karahalios DG, Sonntag VK. Triple anterior screw fixation of an acute combination atlas-axis fracture. Case report. J Neurosurg 1997;87:96-9.

[7] Vaccaro AR, Lehman AP, Ahlgren BD, Garfin SR. Anterior C1-C2 screw fixation and bony fusion through an anterior retropharyngeal approach. Orthopedics 1999;22:1165-70.

[8] Lesoin F, Autricque A, Franz K, et al. Transcervical approach and screw fixation for upper cervical spine pathology. Surg Neurol 1987;27:459-65.

[9] Barbour JR. Screw fixation and fractures of the odontoid process. S Aust Clin 1971;5:20-4.

[10] Guiot B, Fessler RG. Complex atlantoaxial fractures. J Neurosurg 1999;91:139-43.

[11] Abou Madawi A, Solanki G, Casey AT, Crockard HA. Variation of the groove in the axis vertebra for the vertebral artery. Implications for instrumentation. J Bone Joint Surg Br 1997;79:820-3.

[12] Cacciola F, Phalke U, Goel A. Vertebral artery in relationship to C1-C2 vertebrae: an anatomical study. Neurol India 2004;52: $178-84$.

[13] Wright NM, Lauryssen C. Vertebral artery injury in C1-2 transarticular screw fixation: results of a survey of the AANS/CNS section on disorders of the spine and peripheral nerves. American Association of Neurological Surgeons/Congress of Neurological Surgeons. J Neurosurg 1998;88:634-40.

[14] Madawi AA, Casey AT, Solanki GA, et al. Radiological and anatomical evaluation of the atlantoaxial transarticular screw fixation technique. J Neurosurg 1997;86:961-8.

[15] Paramore CG, Dickman CA, Sonntag VK. The anatomical suitability of the C1-C2 complex for transarticular screw fixation. J Neurosurg 1996;85:221-4.

[16] Xu H, Chi YL, Wang XY, et al. Comparison of the anatomic risk for vertebral artery injury associated with percutaneous atlantoaxial anterior and posterior transarticular screws. Spine J 2012;12:656-62.

[17] Lu J, Ebraheim NA, Yang H, et al. Anatomic considerations of anterior transarticular screw fixation for atlantoaxial instability. Spine 1998;23:1229-35; discussion 1236.

[18] Aebi M. Surgical treatment of upper, middle and lower cervical injuries and non-unions by anterior procedures. Eur Spine J 2010;19(1 Suppl): S33-9.

[19] Sen MK, Steffen T, Beckman L, et al. Atlantoaxial fusion using anterior transarticular screw fixation of $\mathrm{C} 1-\mathrm{C} 2$ : technical innovation and biomechanical study. Eur Spine J 2005;14:512-8.

[20] Kim S-M, Lim TJ, Paterno J, et al. Biomechanical comparison of anterior and posterior stabilization methods in atlantoaxial instability. J Neurosurg 2004;100:277-83.

[21] Lapsiwala SB, Anderson PA, Oza A, Resnick DK. Biomechanical comparison of four $\mathrm{C} 1$ to $\mathrm{C} 2$ rigid fixative techniques: anterior transarticular, posterior transarticular, $\mathrm{C} 1$ to $\mathrm{C} 2$ pedicle, and $\mathrm{C} 1$ to $\mathrm{C} 2$ intralaminar screws. Neurosurgery 2006;58:516-21.

[22] Yeom JS, Buchowski JM, Park KW, et al. Undetected vertebral artery groove and foramen violations during $\mathrm{C} 1$ lateral mass and $\mathrm{C} 2$ pedicle screw placement. Spine 2008;33:E942-9.

[23] Park JB, Cho YS, Riew KD. Development of adjacent-level ossification in patients with an anterior cervical plate. J Bone Joint Surg Am 2005;87:558-63.

[24] Kim HJ, Kelly MP, Ely CG, et al. The risk of adjacent-level ossification development after surgery in the cervical spine: are there factors that affect the risk? A systematic review. Spine 2012;37(22 Suppl): S65-74.

[25] Yeom JS, Buchowski JM, Park KW, et al. Lateral fluoroscopic guide to prevent occipitocervical and atlantoaxial joint violation during $\mathrm{C} 1$ lateral mass screw placement. Spine J 2009;9:574-9. 
[26] Lee KM, Yeom JS, Lee JO, et al. Optimal trajectory for the atlantooccipital transarticular screw. Spine 2010;35:1562-70.

[27] Lee JO, Buchowski JM, Lee KM, et al. Optimal trajectory for the occipital Condylar screw. Spine 2012;37:385-92.

[28] Estillore RP, Buchowski JM, Minh DV, et al. Risk of internal carotid artery injury during $\mathrm{C} 1$ screw placement: analysis of 160 computed tomography angiograms. Spine J 2011;11:316-23.
[29] Shin SI, Yeom JS, Kim H-J, et al. The feasibility of laminar screw placement in the subaxial spine: analysis using 215 threedimensional computed tomography scans and simulation software. Spine J 2012;12:577-84.

[30] Riew KD. Commentary: anterior atlantoaxial transarticular screws: should this be the preferred atlantoaxial fixation technique? Spine J 2012;12:663-4. 